Economic and Environmental Geology

Review

\title{
Rayleigh Fractionation of Stable Water Isotopes during Equilibrium Freezing
}

\author{
Jeonghoon Lee ${ }^{*}$, Hyejung Jung, Yalalt Nyamgerel \\ Dept. of Science Education, Ewha Womans University, Seoul 03760, Korea \\ *Corresponding author : jeonghoon.d.lee@gmail.com
}

\section{ARTICLE INFORMATION}

Manuscript received 21 December 2020

Received in revised form 25 January 2021

Manuscript accepted 26 January 2021

Available online 26 February 2021

DOI : http://dx.doi.org/10.9719/EEG.2021.54.1.61

\author{
Research Highlights \\ - Linear relationship between oxygen and hydrogen isotopes for \\ equilibrium freezing \\ - Rayleigh isotopic fractionation for equilibrium freezing \\ - Understanding of isotopic fractionation by freezing is needed for \\ accuracy of paleoclimate studies and hydrographic separation
}

\begin{abstract}
Isotopic compositions of snow or ice have been used to reconstruct paleoclimate and to calculate contribution to streamwater using isotopic hydrograph separation as an end member. During freezing and melting of snow or ice, isotopic fractionation occurs between snow or ice and liquid water. Isotopic evolution during melting process has been studied by field, melting experiments and modeling works, but that during freezing has not been well studied. In this review, isotopic fractionation during equilibrium freezing is discussed using the linear relationship between two stable water isotopes (oxygen and hydrogen) and the Rayleigh fractionation. Snow, evaporated from nearby ocean and condensated, follows the Global Meteoric Water Line (slope of 8), but the melting and freezing of snow affect the linear relationship (slope of 19.5/3.1 6.3). The isotopic evolution of liquid water by freezing observed in the open system during Rayleigh fractionation is also seen in the closed system. The isotopic evolution of snow or ice in the open system where the snow or ice is continuously removed becomes more enriched than the residual liquid water by the fractionation factor. The isotopic evolution of snow or ice in the closed system eventually equals the original isotopic compositions of liquid water. It is expected the understanding of isotopic evolution of snow or ice by freezing to increase the accuracy of the paleoclimate studies and hydrograph separation.
\end{abstract}

Keywords : freezing, melting, stable water isotopes, Global Meteoric Water Line, Rayleigh equation

Citation: Lee, J., Jung, H., Nyamgerel, Y. (2021) Rayleigh Fractionation of Stable Water Isotopes during Equilibrium Freezing, v.54, p.61-67, doi:10.9719/EEG2021.54.1.61.

This is an Open Access article distributed under the terms of the Creative Commons Attribution Non-Commercial License (http://creativecommons.org/ licenses/by-nc/3.0) which permits unrestricted non-commercial use, distribution, and reproduction in any medium, provided original work is properly cited. pISSN 1225-7281; eISSN 2288-7962/C2021 The KSEEG. Printed by Hanrimwon Publishing Company. All rights reserved. 


\section{해설}

\section{평형 냉동에 의한 물동위원소의 레일리분별}

\section{이정훈 ${ }^{*}$ - 정혜정 · 니암게렐 얄랄트}

이화여자대학교 과학교육과

*책임저자 : jeonghoon.d.lee@gmail.com

\section{요 약}

고체상의 눈 또는 얼음의 안정동위원소 값은 과거의 기후를 복원하고 동위원소 수문분리의 단성분으로 기여율을 계산하는 데 에 사용되어 왔다. 융해와 냉동이 일어나면서 눈 또는 얼음과 액체상의 물 사이의 동위원소 분별작용이 일어나는데, 융해는 상 대적으로 현장, 실험 및 모델연구를 통해 연구결과가 제시되어 있지만, 냉동에 대해서는 알려진 것이 많지 않다. 본 논평에서는 평형 냉동이 발생할 때 물의 두 안정동위원소인 산소, 수소의 선형관계 및 레일리분별과정을 통해 냉동에 의한 동위원소 분별 과정을 고찰하였다. 해양에서 증발한 수증기에 의해 응축된 눈은 기울기 8을 가지는 지구천수선을 따라 움직이지만, 냉동 및 융 해가 발생하게 되면 기울기 19.5/3.1 6.3을 가지는 선형관계를 나타내게 된다. 평형냉동 동안 레일리분별과정에 의해 액체상인 물은 열린 계와 닫힌계에서 같은 동위원소변동을 보여 주었다. 눈 또는 얼음이 제거되는 열린 계에서는 남아있는 물의 안정동 위원소와 분별계수만큼의 차이를 가지면서 높은 값을 나타내었다. 닫힌 계에서는 초기 액체상의 물의 동위원소 값으로 눈 또는 얼음은 수렴하였다. 냉동에 의한 눈 또는 얼음의 동위원소변동과정은 고기후 연구 및 수문분리의 정확도를 증가시킬 것으로 기대된다.

주요어 : 냉동, 융해, 물안정동위원소, 지구천수선, 레일리 식

\section{1. 서 론}

고체상인 눈 (snow) 또는 얼음(ice)의 두 안정동위원소 $\left(\delta \mathrm{D}, \delta^{18} \mathrm{O}\right)$ 는 눈 또는 얼음의 생성과정, 과거 기온 복원 및 용융(melting)으로 인한 하천으로의 기여율(contribution) 계산 등에 사용 되어 왔다(Nyamgerel et al., 2020; Lee et al., 2010a; Lee et al., 2010b; Kim et al., 2017; Ham et al., 2019). 눈 또는 얼음의 생성과정을 알기 위해서 주 로 물의 두 안정동위원소의 선형기울기(linear slope)를 계 산해 왔는데, 대표적인 것이 지구천수선(Global Meteoric Water Line, GMWL) 또는 지역천수선(Local Meteoric Water Line, LMWL)이 있다(Lee et al., 2010a; Ham et al., 2019). 지구천수선은 지구상 강수의 산소 및 수소동위원 소의 선형관계를 나타내며 기울기는 8 , 세로축절편은 10 을 가진다 $\left(\delta \mathrm{D}=8 \times \delta^{18} \mathrm{O}+10\right)$ (Dansgaard, 1964). 기울기가 8 보다 작은 값을 가지는 경우에는 다양한 물리적 해석이 가능해 지는데, 예를 들어, 강수의 증발 또는 얼음의 융 해가 발생하게 되면 기울기는 8보다 작은 값을 가지게 된다(Lee et al., 2010). 중수소과잉값(deuterium excess, $\left.d=\delta \mathrm{D}-8 \times \delta^{18} \mathrm{O}\right)$ 은 수증기 기원지의 상대습도를 나타내는 변수로서 강수의 기원이 되는 수증기의 이동을 규명하는 데에 많이 이용되고 있다(Lee et al., 2010a; Kim et al., 2019).
고체상인 얼음을 이용하여 과거의 기후를 복원하는 연 구로서 주로 빙하(ice core)를 지난 50여년동안 이용하여 왔다. 극지역 빙하의 안정동위원소를 분석하여 과거의 온 도, 해양의 상대습도 변화, 해빙의 면적변화 등을 이해하 려고 노력하여 왔다(Nyamgerel et al., 2020). 빙하의 물 안정동위원소변동은 수증기 기원지의 온도변화와 양의 상관성이 있기 때문에, 여름철엔 높은 값을, 겨울철엔 낮 을 값을 나타낸다. 이러한 계절성을 이용하여 눈이 쌓인 이후 융해가 발생하지 않는다면 천부빙하는 연대추정이 가능하다. 빙하연구에서 가장 중요한 과거 온도 복원 역 시 눈에서 얼음으로 변성되는 과정에서 융해가 발생하지 않는다면 물안정동위원소가 기원지의 정보를 가지고 있 기 때문에 물안정동위원소값이 온도의 프록시로 사용되 어 왔다(Mason-Delmotte et al., 2008). 최근 빙하 뿐만 아 니라 얼음쐐기(ice-wedge)를 이용하여 저온환경의 동토지 역에서의 기후변화 연구를 시도하고 있다(Meyer et al., 2015). 특히, 시베리아지역은 최근 기후변화의 영향에 매 우 민감한 지역이며, 우리나라 겨울철 기후에 큰 영향을 끼치는 지역이므로 국내 기후변화 연구에 매우 중요한 의미를 지닐 수 있다. 하지만, 얼음쐐기를 이용한 기온복 원은 얼음쐐기 생성과정에서 융해(melting)와 냉동(freezing) 을 차례로 거치거나, 또는 냉동만을 거치면서 기원지에 서의 온도 정보가 다른 물리적과정에 의해서 동위원소값 
의 분별과정이 발생하게 된다면 오차를 발생시킬 수 있 다(Taylor et al., 2001). 하지만, 냉동에 의한 동위원소분 별과정에 대한 연구는 그다지 많이 이루어지지 않아, 얼 음쐐기로부터 복원된 온도에 대한 검증작업이 필요하다.

동위원소질량분석기(Isotope Ratio Mass Spectrometry, IRMS) 및 그 주변장치의 발달(H-디바이스 및 개스벤치) 과 레이저 흡광법의 원리를 이용한 상업적인 공동 광자 감쇠 분광법(Wavelength Scanned Cavity Ring-Down Spectroscopy, WS-CRDS 또는 Off-Axis Integrated Cavity Output Spectroscopy, OA-ICOS)이 국내에 도입되면서 과 거보다 많은 다양한 연구가 이루어지고 있다(Jung et al., 2013). 전통적으로 지하수 및 강수의 안정동위원소를 분 석하여 충진과정(recharge process) 및 다른 수괴와의 혼 합과정(mixing process)에 대한 연구를 시도하였다(Kim et al., 2017). 최근 극지역에 대한 관심이 높아지면서, 극 지역물순환 연구가 다양한 관점에서 시도되면서, 물안정 동위원소에 대한 사용 및 관심이 높아 지고 있다(Kim et al., 2020; Lee et al., 2020b). 얼음 또는 눈이 융해되면서 융설이 발생 될 때 하천에 도달하는 기작 및 기여율을 연 구하는 동위원소 수문분리법(isotopic hydrograph separation) 을 수행할 때 눈 또는 얼음의 동위원소변동에 대한 연구 가 최근에 보고 되고 있다(Ham et al., 2019). 동위원소 수문분리법을 수계에 적용할 때 눈 또는 얼음의 동위원 소는 변하지 않는다는 것을 가정하고 있는데, 눈 또는 얼 음이 융해되면서 융설이 발생할 때 동위원소 분별과정 (isotopic fractionation)이 발생하며, 이로 인해 오차가 발 생될 수 있음이 보고 되었다(Lee et al., 2014).

눈 또는 얼음의 융해과정에 따른 물안정동위원소의 변 동과정은 여러 연구에 의해 보고 되어 있으나(Taylor et al., 2001; Feng et al., 2002; Taylor et al., 2002; Lee et al., 2009; Lee et al., 2010), 냉동과정에 의한 물안정동위원 소 분별과정에 대한 이해는 국내에서는 시도된 적이 없 으며, 해외에서도 거의 이루어지고 있지 않다(Throckmorton et al., 2016). 따라서, 본 연구에서는 물안정동위원소가 평형냉동과정에서 발생할 수 있는 분별과정에 대하여 논 의하고자 한다. 이를 위하여, 냉동과정 발생 시 수소와 산소동위원소의 선형관계를 파악하고, 물안정동위원소를 설명할 수 있는 레일리(Rayleigh) 분별과정을 도입하여 눈 또는 얼음동위원소의 동위원소분별과정을 설명하고자 한다.

\section{2. 산소-수소 안정동위원소 선형관계}

물순환연구에서 물의 두 안정동위원소인 산소와 수소 의 선형관계(기울기 및 세로축 절편)를 확인하는 방법이
가장 많이 사용되고 있다 (Lee et al., 2010a). GMWL은 지구상의 강우동위원소분포의 특성을 나타내며, 기울기 가 8 , 세로축절편이 10 을 가지는 특성이 있다. 선형관계 에서 기울기는 평형분별(equilibrium fractionation)에 의해 발생하는 것으로 두 안정동위원소의 분별계수에 의해 결 정된다(식 1).

$$
\text { Slope }=\frac{\ln \left(\alpha D_{w-v}\right)}{\ln \left(\alpha^{18} O_{w-v}\right)}
$$

여기에서 $\alpha_{w-v}$ 는 물과 수증기의 평형동위원소분별계 수이다.

선형관계의 기울기가 8 을 가지지 않는 경우에는 다음 과 같이 이해할 수 있다. 강우의 경우 상대습도가 $100 \%$ 가 되지 않아 증발이 발생하였거나, 지하수의 경우에도 천부의 지하수가 증발하였을 경우, 눈의 경우에는 융해 (melting) 또는 승화(sublimation)가 발생하여 동위원소분 별이 일어날 수 있다(Lee et al., 2009; Earman et al., 2006). 따라서, 해양에서 증발한 비 또는 눈이 지표면에 떨어지 면서 어떠한 물리적 과정이 일어나지 않는 다면 기울기 를 8 을 가지지만, 언급된 물리적 기작이 발생하면 8 보다 작은 기울기를 가질 수 있다. 따라서, 눈이 그대로 축적 (accumulation)되어 만들어진 얼음 또는 빙하연구에서 산 소수소동위원소의 기울기를 관찰하는 일은 매우 중요하다.

산소-수소동위원소의 선형관계에서 파생되는 중수소과 잉값(deuterium excess, $\left.d=\delta \mathrm{D}-8 \times \delta^{18} \mathrm{O}\right)$ 은 동력학적분별 (kinetic fractionation)로 발생하는 것으로 강수 및 수증기 의 안정동위원소는 주로 기원하는 해양의 상대습도(relative humidity)에 의해 결정된다. 이론적으로 $100 \%$ 에서 기원 한 수증기의 경우에는 중수소과잉값이 0 에 수렴한다. GMWL에서 나타내는 중수소과잉값 10 은 전 세계 해양 의 평균습도가 $85 \%$ 정도임을 가정하여 발생된 값이며, 수증기가 기원하는 지역에서 습도가 낮은 경우는 10 보다 큰 값을 높은 경우에는 10 보다 작은 값을 가지게 된다. 따라서, 한반도 주변의 강수동위원소 연구에서 중수소과 잉값은 여름철에 10 이하의 값을, 겨울철에 10 이상의 값 을 가지게 된다(Lee et al., 2006). 하지만, 이 역시 수증 기가 해양에서 증발한 후 다른 물리적과정이 일어나지 않은 경우에 기원지의 상대습도를 지시할 수 있으며, 기 울기가 바뀐다면 중수소과잉값에 대한 다른 해석이 필요 할 수 있다.

냉동에 의한 두 물안정동위원소의 변동을 파악하기 위 해서는 융해에 의한 두 물안정동위원소의 분별과정을 이 해하여야 한다. 시간에 따른 눈 또는 얼음의 동위원소분 별과정은 Taylor et al. (2001), Taylor et al. (2002) 및 Ham et al. (2019)에 제시되어 있다. Fig. 1에서는 융해에 의해 


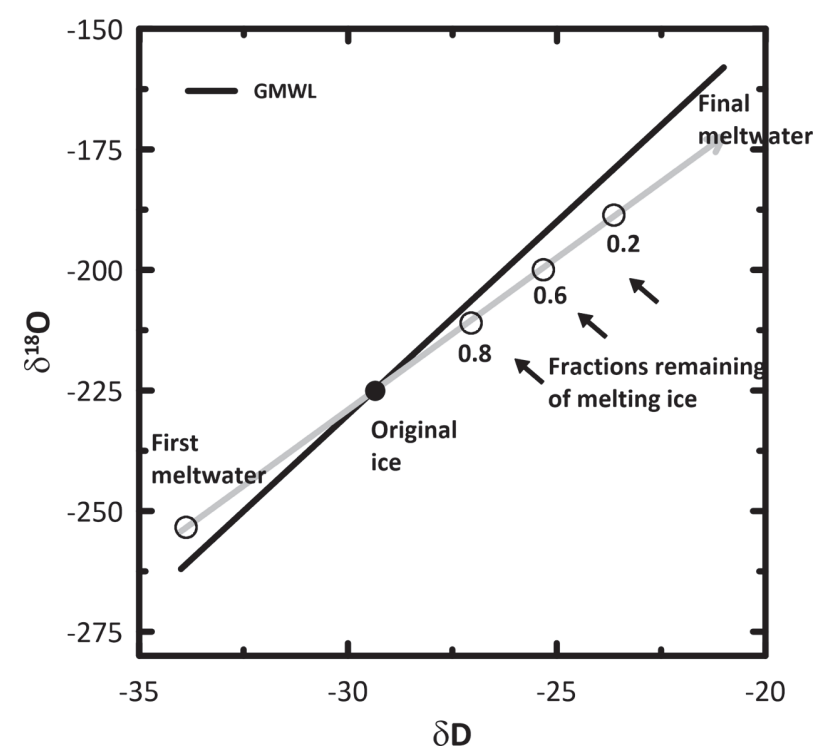

Fig. 1. Theoretical evolution of isotopes in meltwater draining from the base of ice, based on complete equilibrium between the water and ice.

초기 얼음(original ice)으로부터 융해가 발생하면서 얼음 의 안정동위원소가 어떻게 진화(evolution)하는가를 나타 내었다(눈 또는 얼음의 동위원소 초기 값은 균질한 것으 로 가정). 눈 또는 얼음에서 융설이 발생하여 동위원소평 형에 도달하게 되면, 융설의 안정동위원소 조성은 초기 눈 또는 얼음의 안정동위원소 조성에서 두 안정동위원소 의 분별계수만큼 산소는 $3.1 \%$, 수소는 $19.5 \%$ 만큼 낮은 값을 가지게 된다(Lee et al., 2009). 이후 눈 또는 얼음 의 안정동위원소값은 융해가 계속 진행될수록 ${ }^{18} \mathrm{O}$ 또는 $\mathrm{D}$ 가 선택적으로 액체상에 비해 고체상으로 이동하기 때 문에 동위원소 값이 증가하게 된다(Taylor et al., 2001). 고체상인 눈 또는 얼음의 동위원소 값이 증가함에 따라 융설의 동위원소 값도 처음에 감소하였던 값이 계속 증 가하게 된다. 냉동에 의한 두 안정동위원소의 선형관계 는 레일리분별(다음 장)로 설명할 수 있다.

\section{3. 레일리분별(Rayleigh Fractionation)}

레일리분별은 원래 열린계에서 상대적으로 더 큰 저장 소(reservoir)에서 조금씩 물질이 점진적으로 제거되는 중 요한 물리적과정 중에 하나이다(Kendall and McDonnell, 2008). 저장소와 물질이 조금씩 형성되는 즉시 계에서 제 거되거나 고립되게 될 때, 분배계수(distribution coefficient) 또는 평형상수(equlibrium constant)등으로 설명할 수 있 다. 이러한 관계를 Rayleigh (1902)가 하나의 미분방정식 으로 만든 것이 레일리분별 과정이다. 가장 많이 활용되
는 예가 수증기의 응축(condensation), 증류(distillation), 마그마에서 결정이 형성되는 과정등이 있다. 이러한 조 건에서 남아 있는 물질의 동위원소 조성의 변화는 다음 과 같이 설명할 수 있다(Kendall and McDonnell, 1998).

$$
R_{A}=R_{0} F^{(\alpha-1)}
$$

여기에서 $R_{A}$ 는 남아 있는 물질의 동위원소 비율이며, $R_{0}$ 는 저장소의 초기동위원소 값이며, $F$ 는 물질의 남아 있 는 비율이다 $\left(F=X / X_{0}\right)$. 식 2를 바탕으로 열린 계와 닫힌 계에서 냉동이 일어날 때 물의 안정동위원소비에 대하여 논의 할 것이다.

\section{열린 계(Open system)}

평형상태에서 물이 냉동되게 되면 액체상인 물과 고체 상인 얼음사이의 동위원소분별과정은 레일리분별을 따르 게 되며, 얼음과 물의 동위원소 비는 다음과 같이 나타 낼 수 있다.

$$
\begin{aligned}
& R_{\text {liquid }}=R_{\text {liquid }}^{0} F^{(\alpha-1)} \\
& R_{\text {ice }}=\alpha R_{\text {ice }}^{0} F^{(\alpha-1)}
\end{aligned}
$$

동위원소비를 $\delta$ 값으로 전환하기 위해서 식 3 와 4 를 다 음과 같이 나타낼 수 있다.

$$
\begin{aligned}
& \delta_{\text {liquid }}=\left(\delta_{\text {liquid }}^{0}+1000\right) F^{(\alpha-1)}-1000 \\
& \delta_{\text {ice }}=\left(\delta_{\text {liquid }}^{0}+1000\right) \alpha F^{(\alpha-1)}-1000
\end{aligned}
$$

로그값을 이용하여 식동위원소비를 $\delta$ 값으로 전환하기 위해서 식 5 와 6 을 다음과 같이 나타낼 수 있다.

$$
\ln \left(\delta_{\text {liquid }}-\delta_{\text {liquid }}^{0}\right) / 1000=(\alpha-1) \ln F
$$

테일러전개(Taylor series)를 이용하여 다음과 같이 나 타낼 수 있다.

$$
\delta_{\text {liquid }}=\delta_{\text {liquid }}^{0}+1000(\alpha-1) \ln F
$$

얼음의 동위원소값도 액체상의 물과 같이 식을 전개하 면 다음과 같다.

$$
\delta_{\text {ice }}=\delta_{\text {ice }}^{0}+1000 \ln \alpha+1000(\alpha-1) \ln F
$$

$F$ 값은 식 8 을 이용하여 계산할 수 있다. 

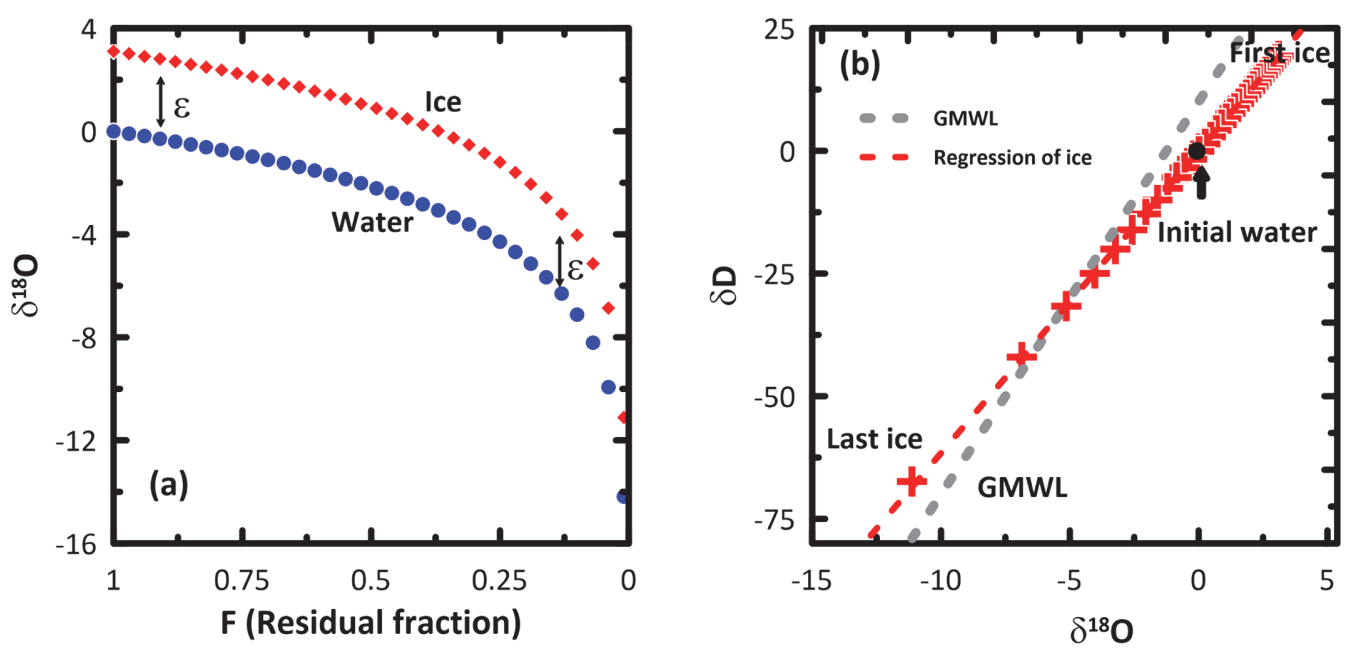

Fig. 2. (a) Isotopic change under open-system Rayleigh conditions for freezing with a fractionation factor $\alpha=1.031$ for an initial liquid composition of $\delta^{18} \mathrm{O}=0$. (b) Linear relationship between $\delta^{18} \mathrm{O}$ and $\delta \mathrm{D}\left(\delta \mathrm{D}=6.16 \times \delta^{18} \mathrm{O}-0.02\right)$.

$$
F=\exp \left[\frac{\delta_{\text {liquid }}-\delta_{\text {liquid }}^{0}}{1000(\alpha-1)}\right]
$$

Fig. $2 \mathrm{a}$ 는 식 8 과 9 를 이용하여 열린계에서의 액체상의 물의 냉동과정에서 이론적인 레일리분별과정이다. 냉동 이 시작하자마자, 첫 번째로 발생한 얼음은 액체상의 물 에 비해 산소동위원소는 $3.1 \%$ 높다(수소동위원소, $19.5 \%$ ) (O’Neil, 1961). 냉동이 진행될수록, 저장소인 액체상의 물에서 ${ }^{18} \mathrm{O}$ 또는 $\mathrm{D}$ 가 고체상으로 선택적으로 이동하기 때문에 저장소는 갈수록 낮은 동위원소 값을 가지게 된 다. 저장소의 동위원소값이 감소하기 때문에 여기서부터 발생되는 얼음의 동위원소 값도 $3.1 \%$ 의 차이를 가지면 서 계속 감소하게 된다. 이는 O'Neil (1968)의 분별계수 값을 사용한 것이며, Suzuoki and Kuruma (1973)의 값을 사용하게 되면 각각 2.8\%o (산소), 20.4\%o (수소) 만큼의 차이가 발생되게 된다.

냉동이 발생하면, 물의 두 안정동위원소의 선형관계는 GMWL에서 Fig. 2b와 같이 진화하게 된다. Fig. $2 \mathrm{a}$ 에서 얼음이 생성되면서 동위원소값이 점점 감소하는 경향이 Fig. 2b에서도 볼 수 있다. 초기 액체상의 물보다 높은 값 에서 얼음이 생성되면서, 열린계에서는 이 얼음은 바로 제거된다. 따라서, 고체상인 얼음과 액체상인 물은 지속 적으로 분별계수(fractionation factor)만큼의 차이를 가지 면서 진화하게 된다. 물의 두 안정동위원소인 산소와 수 소의 선형관계는 냉동을 거치면서 GMWL에서 벗어나게 된다(Lee et al., 2010). 두 안정동위원소의 선형관계에서 기울기는 이론적으로 19.5/3.1 6.3 (O’Neil, 1968), 20.4/ 2.8 7.3 (Suzuoki and Kuruma, 1973) 값을 가져야 하며, O'Neil (1968)이 제시한 값을 이용하면 Fig. 2b와 같이 6.2 를 가지게 된다.

\section{닫힌 계(Closed system)}

열린 계에서는 냉동이 발생하여 생성되는 얼음이 즉시 제거되지만, 닫힌 계에서는 얼음이 제거되지 않고 계속 쌓이게 되면서 얼음 저장소를 형성하게 된다(지하수에서 황산염 환원이 발생할 때 $\mathrm{H}_{2} \mathrm{~S}$ 가 계속 있는 경우와 같음). 닫힌 계에서 얼음이 생성되면서 얼음 저장소의 동위원소 조성은 전체 계의 동위원소 조성으로부터 계산할 수 있 다. 어떠한 시점이더라도, 고체상인 얼음과 액체상인 물 의 두 저장소의 동위원소 비는 다음의 질량보존의 법칙 을 이용할 수 있다.

$$
\delta_{\text {liquid }}^{0}=F \delta_{\text {liquid }}+(1-F) \delta_{\text {ice-reservoir }}
$$

식 8 을 이용하여 식 11 은 다음과 같이 정리될 수 있다. 즉, 생성된 얼음의 저장소의 동위원소 값은 식 12 과 같 이 나타낼 수 있다.

$$
\delta_{\text {ice-reservoir }}=\delta_{\text {liquid }}-\frac{1000(\alpha-1) \ln F}{(1-F)}
$$

식 8 을 이용하여 식 11 은 다음과 같이 정리될 수 있다. 즉, 생성된 얼음의 저장소의 동위원소 값은 식 11 과 같 이 나타낼 수 있다.

Fig. 3a에서는 닫힌 계에서 냉동이 일어날 때 액체상인 물과 얼음의 저장소와 전체 시스템(SYS)의 안정동위원 소의 변화를 나타내었다. $F$ 는 1 이 될 수 없으므로 $F$ 가 1 에 수렴할 때 얼음저장소의 동위원소 값은 분별계수로 수렴하게 된다. 닫힌 계이기 때문에 전체 시스템은 액체 상의 물 $\left(\delta_{\text {liquid }}^{0}=0\right)$ 의 조성과 같아야 하므로, Fig. 3a에 서 일정한 값으로 제시되어 있다. 얼음 저장소의 동위원 

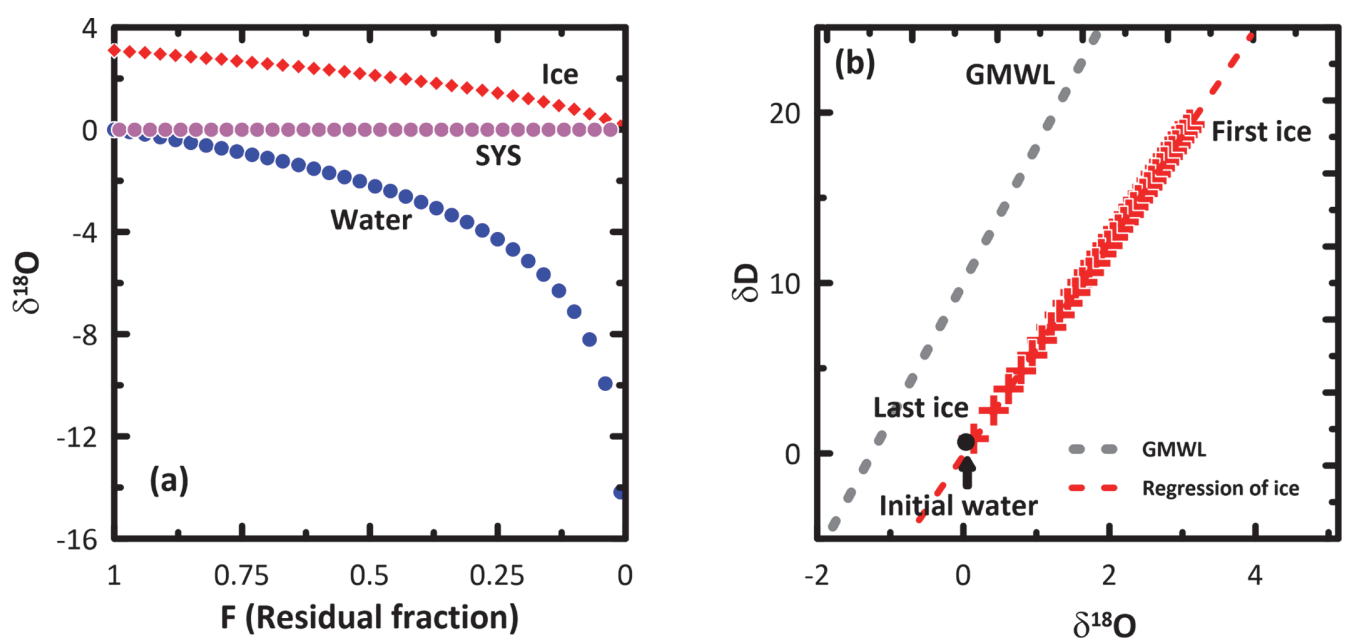

Fig. 3. (a) Isotopic change under closed-system Rayleigh conditions for freezing with a fractionation factor $\alpha=1.031$ for an initial liquid composition of $\delta^{18} \mathrm{O}=0$. SYS represents the isotopic composition of the system. (b) Linear relationship between $\delta^{18} \mathrm{O}$ and $\delta \mathrm{D}$ $\left(\delta \mathrm{D}=6.25 \times \delta^{18} \mathrm{O}-0.12\right)$.

소 조성은 결국 초기 물의 조성에 수렴하여, 질량수지 (mass balance)을 유지할 수 있다. Michel (1986)의 연구 에서는 프로스트 블리스터(frost blister)의 동위원소변동 을 닫힌 계의 레일리분별과정으로 설명하였다. 프로스트 블리스터는 통토(permafrost) 지역에서 활동층(active layer) 가 얼어 붙으면서 높은 지하수 압으로 인해 만들어지는 언덕을 말한다. 활동층위로 공동(cavity)이 지하수에 의해 생성되면서 얼음이 중력방향으로 연속적으로 만들 어 질 수 있다. 이러한 생성과정을 이해하기 위해서 얼음을 위 에서 아랫방향으로 채취하여 안정동위원소를 분석했을 때, Fig. $3 \mathrm{a}$ 의 얼음과 같은 형태를 나타내었다. 따라서, 프 로스트 블리스터에서 얼음의 동위원소 진화과정은 닫힌 계에서 일어났음을 알 수 있다.

닫힌 계에서 산소와 수소의 안정동위원소의 선형관계 는 Fig. 3b와 같다. O'Neil (1968)이 제시한 값을 이용하 여 닫힌 계에서 레일리분별에 의한 기울기 값은 6.3 을 가 지게 된다. 닫힌 계에서는 열린 계와 달리 생성 된 얼음 이 제거되지 않고 계속 남아 있기 때문에 열린 계의 얼 음보다 상대적으로 높은 동위원소 값을 가지게 된다. 하 지만, 액체상의 물의 안정동위원소 값이 낮아지면서 만 들어지는 얼음의 동위원소 값도 낮아지기 때문에 시간이 갈수록 얼음의 두 안정동위원소 값이 낮아지면서 거의 초기 물의 조성에 수렴하게 된다.

\section{4. 요 약}

본 논평에서는 냉동이 발생할 때 액체상인 물과 고체 상인 눈 또는 얼음의 두 안정동위원소의 변동에 대하여
고찰해 보았다. 융해에 의한 물안정동위원소의 변동은 국 내에서도 연구가 제시되어 있지만, 냉동에 의한 연구는 전혀 제시되어 있지 않은 것이 현실이다. 국내에서도 겨 울철 내린 눈이 녹으면서 얼음으로 변성되었다 봄철에 녹는 경우가 대다수이다. 또한, 겨울철 온도의 프록시 중 의 얼음쐐기의 경우에도 겨울철에 내린 눈이 녹거나 바 로 얼면서 생성되기 때문에, 냉동에 의한 안정동위원소 연구를 통해 프록시로서의 정확도를 개선하거나 높일 필 요가 있다.

본 논평에서는 융해와 냉동에 의한 물의 두 안정동위 원소, 산소 및 수소의 선형관계를 고찰하였다. 겨울철에 내리는 눈은 GMWL을 따라 생성되고 쌓이기 시작할 것 이다. 눈 표면의 온도를 영상으로 올리면서 남는 에너지 에 의해서 눈은 녹기 시작할 것이며, 녹은 눈은 다시 얼 기 시작할 것이다. 이 때 동위원소분별작용이 발생하여 기울기 $8(\mathrm{GMWL})$ 에서 6.3 의 기울기를 가지는 쪽으로 진 화할 것이다. 레일리분별과정을 냉동에 적용하여 액체상 인 물은 열린 계와 닫힌계에서 같은 동위원소변동을 보 여 주었지만, 고체상인 눈 또는 얼음은 생성되자마자 제 거되는 열린계에서는 액체상인 물의 안정동위원소와 분 별계수만큼의 차이를 가지면서 감소하였다. 하지만, 닫힌 계에서의 눈 또는 얼음은 액체상인 물에서 생성되면서 계에 계속 존재하면서 저장소를 형성하기 때문에 동위원 소 값은 계속 감소는 하지만 열린 계만큼 감소하지 않고 초기 액체상의 물동위원소값에 수렴하게 된다.

국내 겨울철 기후에 영향을 주는 시베리아 지역의 고 기후 연구를 위해서 얼음쐐기(ice-wedge)를 이용한 연구 가 국내에서도 진행 중에 있다. 얼음쐐기의 물안정동위 
원소를 이용하여 과거의 기온을 복원을 시도하고 있으며, 이를 수행 시 본 논문에서 제안하고 있는 얼음의 용융 또는 냉동에 의한 분화과정을 고려하여야 정확한 온도복 원이 가능할 수 있을 것이라 판단된다(Ham et al., 2019). 최근 눈에 의해 지하수가 충진되는 지역, 강원도, 제주등 에서 눈이 용융되어 얼마만큼 지하수에 기여하는 지에 대한 관심이 높아 지고 있으나 연구는 거의 이루어 지고 있지 않다. 동위원소수문분리를 적용하기 위하여 눈 또 는 얼음의 융해 또는 용융과정이 포함되어야 눈이 얼마 만큼 지하수를 거쳐 하천에 영향을 주는 지 과학적이고 정확하게 계산할 수 있을 것으로 판단된다.

\section{사 사}

이 연구는 연구재단 거대과학연구개발사업 “동시베리 아 얼음쐐기에 기록된 고기후 복원기술 개발(2020M1A5A 1110607)"의 지원으로 이루어졌습니다.

\section{References}

Dansgaard, W. (1964) Stable isotopes in precipitation. Tellus, v.16, p.436-468.

Earman, S., Campbell, A.R., Phillips, F.M. and Newman, B.D. (2006) Isotopic exchange between snow and atmospheric water vapor: estimation of the snowmelt component of groundwater recharge in the southwestern United States. J Geophy Res, v.111, D09302, doi:10.1029/2005JD006470.

Feng, X., Taylor, S., Renshaw, C.E. and Kirchner, J.W. (2002) Isotopic evolution of snowmelt, 1, A physically based one dimensional model. Water Resour Res, v.38, p.1217.

Ham, J.Y., Hur, S.D., Lee, W.S., Han, Y., Jung, H. and Lee, J. (2019) Isotopic variations of meltwater from ice by isotopic exchange between liquid water and ice. J Glaciol, v.65, p.1035-1043.

Jung, Y.Y., Koh, D.C., Lee, J. and Ko, K.S. (2013) Applications of isotope ratio infrared spectroscopy (IRIS) to analysis of stable isotopic compositions of liquid water. Econ Environ Geol, v.46, p.495-508.

Kim, H., Cho, S.H., Lee, D., Jung, Y.Y., Kim, Y.H., Koh, D.C. and Lee, J. (2017) Influence of pre-event water on streamflow in a granitic watershed using hydrograph separation. Environ Earth Sci, v.76, p.82.

Kendall, C. and McDonnell, J.J. (1998) Isotope tracers in catchment hydrology. Elsevier.

Kim, J., Jeen, S.W., Lim, H.S., Lee, J., Kim, O.S., Lee, H., and Hong, S.G. (2000) Hydrogeological characteristics of groundwater and surface water associated with two small lake systems on King George Island, Antarctica. J Hydrol, v.590, p.125537.

Lee, J., Feng, X., Posmentier, E.S., Faiia, A.M. and Taylor, S. (2009) Stable isotopic exchange rate constant between snow and liquid water. Chem Geol, v.260, p.57-62.
Lee, J., Feng, X., Faiia, A.M., Posmentier, E.S., Kirchner, J.W., Osterhuber, R. and Taylor, S. (2010a) Isotopic evolution of a seasonal snowcover and its melt by isotopic exchange between liquid water and ice. Chem Geol, v.270, p.126-134.

Lee, J., Feng, X., Faiia, F., Posmentier, E., Osterhuber, R. and Kirchner, J. (2010b) Isotopic evolution of snowmelt: A new model incorporating mobile and immobile water. Water Resour Res, v.46, W11512, doi:10.1029/2009WR008306.

Lee, J., Hur, S.D., Lim, H.S. and Jung, H. (2020) Isotopic characteristics of snow and its meltwater over the Barton Peninsula, Antarctica. Cold Reg Sci Technol, v.173, p.102997.

Lee, J., Koh, D.C. and Choo, M.K. (2014) Influences of fractionation of stable isotopic composition of rain and snowmelt on isotopic hydrograph separation. J Korean Earth Sci Soc, v. 35, p.97-103.

Lee, K.-S., Park, Y., Kim, Y., Jeong, J.-H., Park, S.-K., Shin, H.-S. and Bong, Y.-S. (2006) A preliminary hydrograph separation study in a small forested watershed using natural tracers. J Geol Soc Korea, v.42, p.427-437.

Mason-Delmotte, V., Hou, S., EKaykin, A., Jouzel, J., Aristarain, A., Bernardo, R.T., Bromwich, D., Cattani, O., Delmotte, M., Falourd, S., Frezzotti, M., Gallée, H., Genoni, L., Isaksson, E., Landais, A., Helsen, M.M., Hoffmann, G., Lopez, J., Morgan, V., Motoyama, H., Noone, D., Oerter, H., Petit, J.R., Royer, A., Uemura, R., Schmidt, G.A., Schlosser, E., Simões, J.C., Steig, E.J., Stenni, B., Stievenard, M., van den Broeke, M.R., van de Wal, R.S.W., van de Berg, W.J., Vimeux, F. and White, J.W.C. (2008) A review of Antarctic surface snow isotopic composition: Observations, atmospheric circulation, and isotopic modeling. J of Clim, v.21, p.3359-3387.

Michel, F.A. (1986) Isotope geochemistry of frost-blister ice, North Fork Pass, Yukon, Canada. Can J Earth Sci, v.23, p.543-549.

Meyer, H., Opel, T., Laepple, T., Dereviagin, A.Y., Hoffmann, K. and Werner, M. (2015) Long-term winter warming trend in the Siberian Arctic during the mid-to late Holocene. Nature Geosci, v.8, doi:10.10385/NGEO02349.

Nyamgerel, Y., Han, Y., Kim, S., Hong, S.B., Lee, J. and Hur, S.D. (2020) Chronological characteristics for snow accumulation on Styx Glacier in northern Victoria Land, Antarctica. J Glaciol, v.66, p.916-926.

O’Neil, J.R. (1968) Hydrogen and oxygen isotope fractionation between ice and water. J Phys Chem, v.72, p.3683-3684.

Lord Rayleigh (1902) On the distillation of binary mixture. Phil Mag, v.4, p.521-537.

Suzuoki, T. and Kumura, T. (1973) D/H and ${ }^{18} \mathrm{O} /{ }^{16} \mathrm{O}$ fractionation in ice-water systems. Mass Spectro, v.21, p.229-233.

Taylor, S., Feng, X., Kirchner, J.W., Osterhuber, R., Klaue, B. and Renshaw, C.E. (2001) Isotopic evolution of a seasonal snowpack and its melt. Water Resour Res, v.37, p.759-769.

Taylor, S., Feng, X., Kirchner, J.W., Osterhuber, R., Klaue, B. and Renshaw, C.E. (2001) Isotopic evolution of a seasonal snowpack and its melt. Water Resour Res, v.37, p.759-769.

Throckmorton, H.M., et al. (2016) Active layer hydrology in an arctic tundra ecosystem: quantifying water sources and cycling using water stable isotopes. Hydrol Process, v.30, p.4972-4986. 